\title{
Comparative in vitro study of the antimicrobial activities of different commercial antibiotic products of vancomycin
}

\author{
Jorge A Diaz ${ }^{1 \dagger}$, Edelberto Silva ${ }^{1 *+}$, Maria J Arias $^{2}$ and María Garzón ${ }^{1}$
}

\begin{abstract}
Background: One of the most critical problems about antimicrobial therapy is the increasing resistance to antibiotics. Previous studies have shown that there is a direct relation between erroneous prescription, dosage, route, duration of the therapy and the antibiotics resistance. Other important point is the uncertainty about the quality of the prescribed medicines. Some physicians believe that generic drugs are not as effective as innovator ones, so it is very important to have evidence that shows that all commercialized drugs are suitable for therapeutic use.

Methods: Microbial assays were used to establish the potency, the Minimal Inhibitory Concentrations (MICs), the Minimal Bactericidal Concentration (MBCs), the critical concentrations, and the production of spontaneous mutants that are resistant to vancomycin.

Results: The microbial assay was validated in order to determine the Vancomycin potency of the tasted samples. All the products showed that have potency values between 90 - 115\% (USP requirement). The products behave similarly because the MICs, The MBCs, the critical concentrations, the critical concentrations ratios between standard and samples, and the production of spontaneous mutants don't have significant differences.

Conclusions: All products analyzed by microbiological tests, show that both trademarks and generics do not have statistical variability and the answer of antimicrobial activity Show also that they are pharmaceutical equivalents.
\end{abstract}

\section{Background}

Pharmaceutical products, especially antibiotics, must comply with standards of quality, efficacy and reliability, attributes that are determined by various authorities $[[1,2]$, and [3]]. A discussion about the quality and efficacy of generic antibiotics has taken place in recent decades. This discussion has included presentations in congress and research articles in which the authors have shown that some products do not meet regulatory standards $[4,5]$ and that their behavior is not similar in animal models $[6,7]$

Some antibiotics must be analyzed using biological assays (e.g., penicillin, amikacyn, vancomycin, and neomycin) [2]. These products are measured by their potency or biological activity compared against an

\footnotetext{
* Correspondence: esilvag@unal.edu.co

† Contributed equally

${ }^{1}$ Universidad Nacional de Colombia, Facultad de Ciencias, Departamento de Farmacia, Laboratorio de Asesorías e Investigaciones en Microbiología, 472. Ciudad Universitaria. Carrera 30 Calle 45. A.A.14490. Bogotá D. C. Colombia Full list of author information is available at the end of the article
}

international standard. Therefore, the commercial products must be similar in composition to the international reference standard [7]. With antibiotics like vancomycin, if the commercial products do not fulfill the requirements of pharmacopeia, their behavior and performance could put a patient's health in danger.

Biological assays and other analytical procedures must be validated before they are applied in the analysis of the content of the antibiotic under study because, otherwise, neither the information or data generated nor conclusions obtained will be reliable [3]. Our worry arises from the fact that some researchers confuse a "gold standard" with an international reference standard for quantification. A gold standard is something that is a defined commercial product used as reference of performance in comparative studies. It is not a reference standard, but another commercial product with its own variation. Gold standards are established for purposes of bioequivalence and bioavailability studies [2], but in the case of IV antibiotics, the bioavailability is $100 \%$, and therefore, pharmacodynamic
C Biomed Central

(c) 2011 Diaz et al; licensee BioMed Central Ltd. This is an Open Access article distributed under the terms of the Creative Commons Attribution License (http://creativecommons.org/licenses/by/2.0), which permits unrestricted use, distribution, and reproduction in any medium, provided the original work is properly cited. 
studies must be supported with validated analytical results [2].

Our group has been focusing on developing validated techniques using proper international reference standards to evaluate the content or potency of commercial antibiotics. These techniques can be used in performance studies like those for the determination of a Minimal Inhibitory Concentration (MIC), Minimal Lethal Concentration, Critical Concentration and production of Spontaneous Mutants [8,9].

This paper presents the results for the evaluation of commercial products of vancomycin to describe some issues that are important in the evaluation of antibiotics.

\section{Methods}

\section{Microorganisms}

THE UNITED STATES PHARMACOPOEIA XXVII states that spores of Bacillus subtilis ATCC 6633 are the source of this microorganism used to develop a microbiological assay for evaluating the potencies of vancomycin products. For MIC and MBC studies, we used Acinetobacter baumanii strains 59, 139, 147 and 173, Enterococcus gallinarum, Streptococcus faecalis ATC 29212, a nosocomial strain 319623 and a vancomycin-sensitive strain, Escherichia coli strains 39, 50 and 69, Klebsiella pneumoniae strains 1, 43, 63, 65 and 207, Pseudomonas aeruginosa strains 42, 74, 151, 157, and HE1, Staphylococcus aureus strains 287, 291 and ATCC 25923, and Morganella morganii HE2. All of the microorganisms were grown in Mueller Hinton (MH) broth (incubated at $35^{\circ} \mathrm{C}$ for $24 \mathrm{~h}$ ). Each strain was then plated on $\mathrm{MH}$ agar to obtain isolated colonies, which were then used to make larger cultures in $\mathrm{MH}$ medium. The cultures were harvested with cryopreservation broth. A portion of each was kept in a cryovial at $-70^{\circ} \mathrm{C}$, and the other portion was used to prepare a suspension with $25 \%$ transmittance at $600 \mathrm{~nm}(25 \% \mathrm{~T})$ to develop in vitro assays. These suspensions were kept in cryovials at $-70^{\circ} \mathrm{C}$.

\section{Analytical Bioassay}

An analytical bioassay was established and validated for vancomycin. First, the proper concentration range was determined, and then the linearity, precision, specificity and stability of the compound in question were assessed $[2,3]$. All of the samples were evaluated with this analytical bioassay under the chosen conditions.

\section{Minimal Inhibitory Concentration (MIC) and Minimal Bactericidal Concentration (MBC)}

Assays to assess these parameters were developed in two parts. (1) Preparation of inocula: the number of colony forming units (CFUs) was determined for each suspension at $25 \% \mathrm{~T}$ to prepare inocula of $1-5 \times 10^{6} \mathrm{CFUs} / \mathrm{ml}$.
(2) MIC and MBC determination by micro-dilution: samples were diluted to $2 \mathrm{mg} / \mathrm{ml}$ for evaluation. Using a multichannel pipette, $100 \mu \mathrm{l}$ Mueller Hinton Broth was placed in each well of a 96-well ELISA plate, with $200 \mu \mathrm{l}$ in column 12. Next, $100 \mu \mathrm{l}$ of the antibiotic solution $(2 \mathrm{mg} / \mathrm{ml})$ was placed in the first column and thoroughly mixed by pipetting. From these wells, $100 \mu \mathrm{l}$ was added to the second column and mixed, and this procedure was repeated up to column 10, after which the $100-\mu l$ portion was discarded. Columns 11 and 12 were positive and negative controls, respectively. Each row (A to $\mathrm{H}$ ) represented a different sample to be analyzed. Each inoculum $(100 \mu \mathrm{l})$ was then pipetted into each microplate, which was incubated at $37^{\circ} \mathrm{C}$ for $24 \mathrm{~h}$. Growth in the wells was assessed. The lowest dilution showing no growth, the first dilution with growth, and the two controls were plated onto MH agar. The MIC was defined as the lowest dilution that showed no growth on the ELISA plate but showed growth on $\mathrm{MH}$ agar. The $\mathbf{M B C}$ was defined as the lowest dilution that did not show growth on either the ELISA plate or MH agar [10].

\section{Critical Concentration (CC)}

The CC was determined similarly to the analytical bioassay. The inocula for MIC and MBC determinations and two-fold serial dilutions of each sample from 993 to $31,03 \mu \mathrm{g} / \mathrm{ml}$ were used (The batch of Vancomycin USP standard has a potency of $99300 \mu \mathrm{g}$ per vial). The halo of inhibition was measured, and the crown length (X) was calculated (the inhibition halo diameter minus the reservoir diameter divided by 2 ). The log concentration vs. $\mathrm{X}^{2}$ was plotted, and a linear regression $(y=m x+b)$ was applied. The y-intercept $(b)$ is equivalent to the log of the CC [10].

\section{Spontaneous mutants}

Spontaneous mutation was analyzed similarly to the analytical bioassay. Again, the inocula for the MIC and MBC determinations were used. Specific microorganisms and dilutions were selected after determinations of critical concentrations. On each plate, a dilution of the USP standard and samples of the same concentration were used.

\section{Samples}

Commercial products purchased from the pharmacies of different hospitals in Bogotá, D. C. Colombia, were analyzed. They included trademarked products and generic products of vancomycin. All of the samples had declared contents of $500 \mathrm{mg}$. They were all diluted in sterile water in $100 \mathrm{ml}$ volumetric flasks. The solutions were divided into $5-\mathrm{ml}$ fractions for storage at $-70^{\circ} \mathrm{C}$ and were diluted to $1 \mathrm{mg} / \mathrm{ml}$ to develop the analytical bioassays. 


\section{Statistical Analysis}

All the assays were performed three times, and the statistical tool of Microsoft Excel ${ }^{\circledR}$ was applied to analyze the dates.

\section{Results}

\section{Analytical Bioassay}

The United Stated Pharmacopoeia XXVII recommends Bacillus subtilis ATCC 6633 as the biological organism to use to develop the analytical bioassay for vancomycin products. Figure 1 shows the results of this bioassay.

\section{Determination of concentration range, incubation time and} culture medium $\mathrm{pH}$

Ten concentrations were used to determine the concentration range (two-fold dilutions from 1005 to $1.96 \mu \mathrm{g} / \mathrm{ml}$, because this batch of Vancomycin USP standard has a potency of $100500 \mu \mathrm{g} / \mathrm{vial})$. Table 1 shows that the best linearity was in the range between C3 and C8 (251.25 to $7.85 \mu \mathrm{g} / \mathrm{ml})\left(\mathrm{R}^{2}=0.9907\right.$, Figure 2$)$.

The assay required an 8 to $10 \mathrm{~h}$ incubation time at $37^{\circ} \mathrm{C}$. This incubation is shorter than many common assays, which require between 18 and $24 \mathrm{~h}$.

The results for Vancomycin show that a $\mathrm{pH}$ of 6.4 or 6.5 is optimal because growth was abundant and homogenous, and inhibition haloes were well defined at this pH (Table 2).

\section{Linearity}

In Tables 3 and 4, the concentration of antibiotic correlates well with the diameter of the zone of inhibition.

From this point on, the selected concentrations will be designated C1 to C6 for clarity.

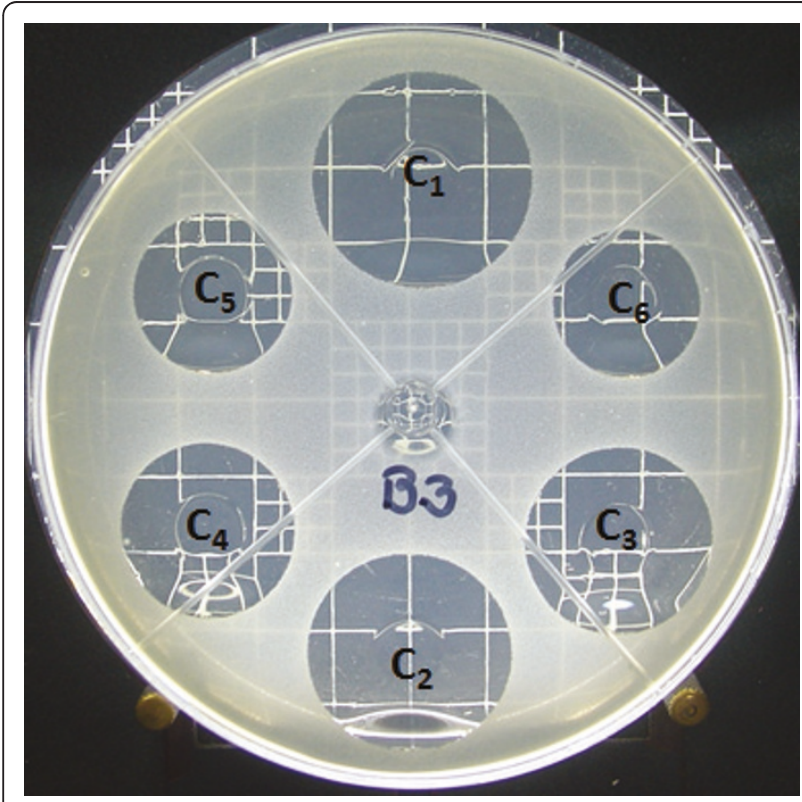

Figure 1 Bioassay of Vancomycin (USP standard) against Bacillus subtilis ATCC 6633.
Table 1 Evaluation of the range of concentrations for Vancomycin (USP standard)

\begin{tabular}{ccccc}
\hline \multicolumn{2}{c}{ Concentration Range } & \multicolumn{3}{c}{ Equation } \\
\hline From & To & Slope & Intercept & $\mathbf{R}^{\mathbf{2}}$ \\
\hline C1 & C6 & 2.462680435 & 6.415123505 & 0.996221756 \\
C2 & C7 & 2.324635129 & 7.259328533 & 0.989384179 \\
C3 & C8 & $\mathbf{2 . 2 7 0 2 2 4 7 7 7}$ & $\mathbf{7 . 3 6 2 3 8 6 3 2 6}$ & $\mathbf{0 . 9 9 0 6 8 2 6 2 5}$ \\
C4 & C9 & 2.367915749 & 6.864768679 & 0.98750859 \\
\hline
\end{tabular}

Cited on page 6

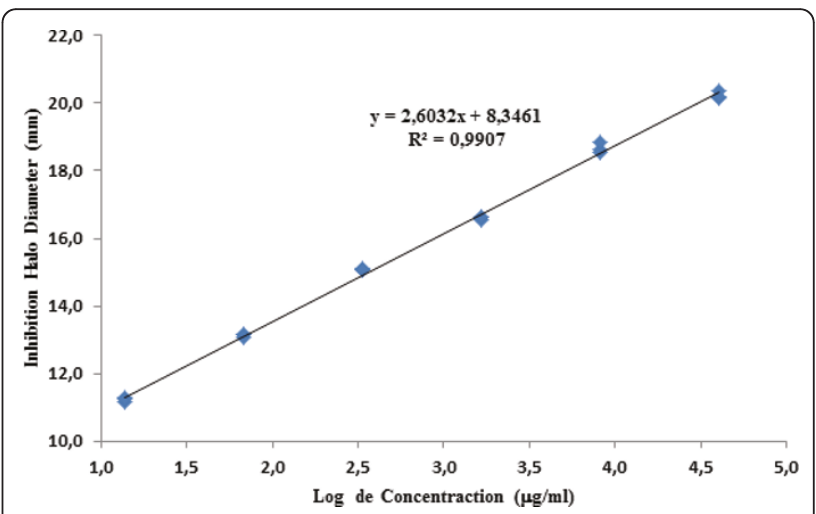

Figure 2 Calibration curve of Vancomycin (USP standard) used to evaluate the linearity of the optimal concentration range.

Table 2 Evaluation of the pH effect on linearity

\begin{tabular}{cccc}
\hline $\mathbf{p H}$ & Equation & $\mathbf{R}^{\mathbf{2}}$ & Incubation Time \\
\hline 5.4 & $y=1.8463 x+14.882$ & 0.9806 & 8 hours \\
5.9 & $y=2.3895 x+19.128$ & 0.9898 & 8 hours \\
$\mathbf{6 . 4}$ & $\mathbf{y}=\mathbf{1 . 5 5 1 7 x}+\mathbf{1 1 . 8 1 7}$ & $\mathbf{0 . 9 9 7 7}$ & $\mathbf{8}$ hours \\
$\mathbf{6 . 5}$ & $\mathbf{y}=\mathbf{2 . 1 3 4 x}+\mathbf{7 . 4 1 1 3}$ & $\mathbf{0 . 9 9 7 5}$ & $\mathbf{8}$ hours \\
7 & $y=1.7824+11.212$ & 0.9794 & 9 hours \\
7.5 & $y=1.875 x+11.009$ & 0.9663 & 10 hours \\
8 & $y=2.3651 x+9.3311$ & 0.9763 & 11 hours \\
\hline
\end{tabular}

Cited on page 6 .

Table 3 Evaluation of the linearity of Vancomycin

\begin{tabular}{ccccc}
\hline Test & HYPOTHESIS & Experimental $\mathbf{t}$ & Theoretical $\mathbf{t}$ & Decision \\
\hline Slope & $H_{0}: m=0$ & 19.7 & 2.120 & Reject $H_{0}$ \\
& $H_{1}: m \neq 0$ & & & \\
Intercept & $H_{0}: b=0$ & 125.3 & 2.120 & Reject $H_{0}$ \\
& $\begin{array}{l}H_{1}: b \neq 0 \\
\text { Correlation }\end{array}$ & & & \\
& $H_{0}: R=0$ & 67.5 & 2.120 & Reject $H_{0}$ \\
& $H_{1}: R \neq 0$ & & & \\
\hline
\end{tabular}

Cited on page 6. 
Table 4 Regression analysis by analysis of variance (ANOVA)

\begin{tabular}{|c|c|c|c|c|}
\hline Test & HYPOTHESIS & Experimental $\mathrm{t}$ & Theoretical t & Decision \\
\hline Regression & $\begin{array}{l}\mathrm{H}_{0}: \text { There is no regression } \\
\mathrm{H}_{1} \text { : There is regression }\end{array}$ & 146.6 & 4.670 & Reject $\mathrm{H}_{0}$ \\
\hline Deviation from Linearity & $\begin{array}{l}\mathrm{H}_{0} \text { : There is no deviation from linearity } \\
\mathrm{H}_{1} \text { : There is a deviation from linearity }\end{array}$ & -3.0 & 3.71 & Accept $\mathrm{H}_{c}$ \\
\hline
\end{tabular}

Cited on page 6.

\section{Precision}

The reproducibility and between-day precision of our assays were evaluated in several ways. Reproducibility was studied by determining the coefficient of variation, which was less than $1 \%$ and was acceptable for analytical assays in the pharmaceutical industry (Table 5).

The between-day precision was also analyzed. Analysis of variance (ANOVA) showed that, for the antibiotic evaluated, the results of assays performed on different days did not significantly differ (Table 6).

\section{Stability}

The stability of each compound during the experimental period was verified. Solutions of vancomycin in water and phosphate buffer, pH $4.5(1005 \mu \mathrm{g} / \mathrm{ml}$; USP Standard), were incubated at $37^{\circ} \mathrm{C}, 18^{\circ} \mathrm{C}$ and $4^{\circ} \mathrm{C}$, and samples were taken after 24,48 , and 86 hours or seven and fifteen days of incubation. The samples (Vancomycin Standard Solution) under different treatments, were diluted fromC1 to C6 to perform the relation Log Concentration vs. Halo Diameter Inhibition, and the results were plotted and compared to reveal any reduction in antibiotic activity (i.e., a decrease in the diameter of the zone of inhibition).

From the equation $y=m x+b$, where $y$ represents the inhibition zone diameter and $x$ represents the log of the concentration, changes in the value of $b$ indicate changes in activity. If there is no change in the intercept, the antibiotic is stable. If the value of $b$ decreases, this trend indicates instability or a loss of activity.

The solutions showed a slight decrease in the intercept values after $24 \mathrm{~h}$ of at each storage temperature (Tables 7 and 8). From this result, it appears that the molecule remained stable during our assays ( 48 hours at

Table 5 Reproducibility of assays using Vancomycin (Cochran Test)

\begin{tabular}{lllllll}
\hline $\begin{array}{c}\text { Concentration } \\
(\mathbf{m g} / \mathbf{m l})\end{array}$ & $\mathbf{2 5 1 . 2 5}$ & $\mathbf{1 6 5 . 6 3}$ & $\mathbf{6 2 . 8 5}$ & $\mathbf{3 1 . 4 1}$ & $\mathbf{1 5 . 7 0}$ & $\mathbf{7 . 8 5}$ \\
\hline $\begin{array}{c}\text { Standard } \\
\text { deviation }\end{array}$ & 0.096 & 0.076 & 0.237 & 0.084 & 0.100 & 0.270 \\
$\begin{array}{c}\text { Variance } \\
\text { Coefficient }(\%)\end{array}$ & 0.4759 & 0.408422 & 1.4576 & 0.559623 & 0.7061 & 2.2425 \\
Variance $\left(\mathbf{S}^{2}\right)$ & 0.0092 & 0.00583 & 0.0113 & 0.00707 & 0.0099 & 0.01213 \\
\hline Sum $\left(\mathbf{S}^{2}\right)$ & & & & & & 0.05544 \\
\hline Cited on page 6. & & & & & &
\end{tabular}

$\left.37^{\circ} \mathrm{C}\right)$. Therefore, the assay results reflect the exact potency of the product.

\section{Specificity}

To test specificity, solutions of the antibiotics were incubated at $50^{\circ} \mathrm{C}$. The vancomycin solutions lost a small amount of activity (3\% to $4 \%$ ) after 15 days, but after 30 days, there was no longer any activity, meaning that vancomycin was the only molecule in solution responsible for the antimicrobial activity (Table 9).

\section{Sample analysis}

The samples were analyzed with the previously validated assay. The results were quantified using the statistical method described by Hewitt (1977). Table 10 shows the content of vancomycin in the samples purchased, and in each case, the values fulfill the criteria laid out by USP XXV II for intravenous vancomycin: “...Contents no less than $\mathbf{9 0 \%}$ and no more than $115 \%$ of Vancomycin, calculated on anhydrous base of the quantity registered of Vancomycin".

\section{Minimal inhibitory and bactericidal concentrations}

Using the previously described methods, the samples were analyzed in groups of seven per plate, and each plate was inoculated with a single bacterial strain. The first row of the plate contained the USP standard; the other seven rows contained the samples. Figure 3 shows the results for vancomycin products. The plates showed the same performance for the standard as for the samples.

Growth was inhibited at the same concentration of each sample. After transfer onto $\mathrm{MH}$ agar, there was no growth in concentrations $\mathrm{C} 1$ to $\mathrm{C} 5$ or $\mathrm{C} 12$, but there was growth in $\mathrm{C} 6$ to $\mathrm{C} 11$. This result means that the antibiotic has an

Table 6 ANOVA of the between-day precision of assays using Vancomycin

\begin{tabular}{cccc}
\hline Concentration & Experimental $\mathbf{F}$ & Theoretical $\mathbf{F}$ & Decision \\
\hline C1 & 0.041 & 4.96 & Accept $\mathrm{H}_{0}$ \\
C2 & 0.047 & 4.96 & Accept Ho \\
C3 & 0.069 & 4.96 & Accept Ho \\
C4 & 0.093 & 4.96 & Accept Ho \\
C5 & 0.128 & 4.96 & Accept Ho \\
C6 & 0.182 & 4.96 & Accept $\mathrm{H}_{0}$ \\
\hline
\end{tabular}

Cited on page 6. 
Table 7 Stability of Vancomycin in water for injection at $4^{\circ} \mathrm{C}, 18^{\circ} \mathrm{C}$ and $37^{\circ} \mathrm{C}$

\begin{tabular}{cccccccccc}
\hline Time & \multicolumn{3}{c}{$\mathbf{4}^{\circ} \mathbf{C}$} & \multicolumn{3}{c}{$\mathbf{1 8}^{\circ} \mathbf{C}$} & \multicolumn{3}{c}{$\mathbf{3 7 ^ { \circ } \mathbf { C }}$} \\
\cline { 2 - 9 } & Slope & Intercept & $\mathbf{R}^{\mathbf{2}}$ & Slope & Intercept & $\mathbf{R}^{\mathbf{2}}$ & Slope & Intercept & $\mathbf{R}^{\mathbf{2}}$ \\
\hline $\mathbf{0 ~ h}$ & 1.5177 & 12.556 & 0.9913 & 1.5177 & 12.556 & 0.9913 & 1.5177 & 12.556 & 0.9913 \\
$24 \mathrm{~h}$ & 1.5305 & 12.543 & 0.9908 & 1.5241 & 12.518 & 0.9916 & 1.5063 & 12.5210 & 0.9900 \\
$48 \mathrm{~h}$ & 1.522 & 12.544 & 0.9919 & 1.518 & 12.501 & 0.9926 & 1.4936 & 12.495 & 0.9924 \\
$86 \mathrm{~h}$ & 1.5224 & 12.509 & 0.9916 & 1.5178 & 12.461 & 0.9924 & 1.4981 & 12.4720 & 0.9928 \\
7 days & 1.5165 & 12.4780 & 0.9919 & 1.5217 & 12.342 & 0.9935 & 1.4742 & 12.3040 & 0.9904 \\
15 days & 1.5247 & 12.3460 & 0.9921 & 1.5041 & 12.273 & 0.9923 & 1.4425 & 12.1980 & 0.9916 \\
\hline
\end{tabular}

Cited on page 7.

MBC but no MIC. The MBC is C5 for the USP standard and for all the samples. For all of the samples, using all of the microorganisms evaluated, the results showed that the samples had the same performances at each repetition of the assay (Table 11 includes results for only some samples as an illustration).

\section{Critical concentration (CC)}

The CC is the minimum concentration that inhibits microorganism growth. It occurs at the limit of the inhibition halo. It is a measure of a microorganism's sensitivity and can be different from the MIC, which is determined under different conditions. The $\mathrm{CC}$ can be defined mathematically as $\operatorname{Ln}(C C)=\operatorname{Ln}\left(C_{O}\right)-X^{2} / D^{O}$, where $\mathrm{CC}$ is the critical concentration, $\mathrm{C}_{\mathrm{O}}$ is the antibiotic concentration in the reservoir, $\mathrm{X}$ is the length of the crown (see above), D is the diffusion coefficient, and $\mathrm{T}_{\mathrm{O}}$ is the critical time. The intercept of a plot of $\mathrm{Ln}$ $\left(\mathrm{C}_{\mathrm{O}}\right)$ vs. $\mathrm{X}^{2}$ is the $\mathrm{Ln}$ of CC [7].

Figure 4 shows the different behaviors of the microorganisms tested with the vancomycin standard. In Figures $4 \mathrm{~A}$ and $4 \mathrm{~B}$, the microorganisms exhibited growth of spontaneous mutants. Figure $4 \mathrm{C}$ shows a microorganism resistant to vancomycin, and, finally, Figures $4 \mathrm{D}, \mathrm{E}$ and 4F correspond to microorganisms with well-defined haloes, allowing for a comparison of the performances of the products tested for development. A well-defined inhibition halo was the selection criterion for evaluating CCs. For the CC assays, E. faecalis, E. faecalis ATCC 29212, E. faecalis 319623, A. baumanii 59, E. gallinarum, P. aeruginosa 43 and 74, S. aureus 281, 291 and
ATCC 25923 were selected. Figure 5 shows the correlation of $\mathrm{X}^{2}$ with the $\log$ of antibiotic concentration. The regression equation is $y=0.0353 x+0.9297$, and $b$ is therefore 0.9287. The $\mathrm{CC}$ is equivalent to antilog (0.9297), i.e., $8.506 \mu \mathrm{g} / \mathrm{ml}$.

The $\mathrm{CC}$ values for the different vancomycin products showed no significant differences, meaning that the products behaved in similar ways against the different microorganisms tested (Table 12). On this basis, the generic products meet all of the quality standards applied to the pharmaceutical products and perform as well as the newest versions of these products.

In addition, the ratio between the sample CCs and standard CCs are similar to the ratios of antibiotic contents. In other words, all samples perform the same with regard to their antimicrobial activities in vitro (Table 13).

\section{Spontaneous mutants}

It was noted in the previous assays that some strains produced spontaneous mutants (Figure 4A), as indicated by the appearance of colonies within the inhibition halo. Therefore, an assay to assess spontaneous mutation was developed with appropriate concentrations of antibiotics. Each experimental setup included an agar plate inoculated with a test strain. Of the six reservoirs, two contained standard solutions and the other four contained sample solutions. The numbers of mutants produced by the standard and sample solutions were counted after incubation.

For the spontaneous mutant assays, the strains selected were S. aureus 291 as a control strain (showing no production of spontaneous mutants) and A. baumanii 54 and

Table 8 Stability of Vancomycin in phosphate buffer, pH 4

\begin{tabular}{cccccccccc}
\hline Time & \multicolumn{3}{c}{$\mathbf{4}^{\circ} \mathbf{C}$} & & & $\mathbf{1 8}^{\circ} \mathbf{C}$ & \multicolumn{3}{c}{$\mathbf{3 7}^{\circ} \mathbf{C}$} \\
\cline { 2 - 9 } & Slope & Intercept & $\mathbf{R}^{\mathbf{2}}$ & Slope & Intercept & $\mathbf{R}^{\mathbf{2}}$ & Slope & Intercept & $\mathbf{R}^{\mathbf{2}}$ \\
\hline $0 \mathrm{~h}$ & 1.4807 & 12.799 & 0.9916 & 1.4807 & 12.799 & 0.9916 & 1.4807 & 12.799 & 0.9916 \\
$24 \mathrm{~h}$ & 1.4910 & 12.7640 & 0.9917 & 1.4833 & 12.764 & 0.9917 & 1.5195 & 12.5150 & 0.9916 \\
$48 \mathrm{~h}$ & 1.487 & 12.733 & 0.9924 & 1.4747 & 12.716 & 0.9928 & 1.509 & 12.497 & 0.9922 \\
$86 \mathrm{~h}$ & 1.4787 & 12.7260 & 0.9933 & 1.4701 & 12.689 & 0.9927 & 1.5057 & 12.4700 & 0.9915 \\
7 days & 1.4804 & 12.6510 & 0.9925 & 1.4766 & 12.571 & 0.9931 & 1.4966 & 12.3800 & 0.9922 \\
15 days & 1.4826 & 12.5170 & 0.9937 & 1.4566 & 12.505 & 0.9932 & 1.4887 & 12.2510 & 0.9926 \\
\hline
\end{tabular}

Cited on page 7. 
Table 9 Stability of Vancomycin in phosphate buffer, pH 4

\begin{tabular}{ccccccc}
\hline \multirow{2}{*}{ Time } & \multicolumn{3}{c}{ Phosphate Buffer, pH 4.5 } & \multicolumn{3}{c}{ Water For Injection } \\
\cline { 2 - 7 } & Slope & Intercept & $\mathbf{R}^{\mathbf{2}}$ & Slope & Intercept & $\mathbf{R}^{\mathbf{2}}$ \\
\hline $\mathrm{O} \mathrm{h}$ & 1.4807 & 12.799 & 0.9916 & 1.5177 & 12.556 & 0.9913 \\
$24 \mathrm{~h}$ & 1.5268 & 12.4310 & 0.9909 & 1.5059 & 12.4640 & 0.9905 \\
$48 \mathrm{~h}$ & 1.4924 & 12.479 & 0.9912 & 1.4907 & 12.409 & 0.993 \\
$86 \mathrm{~h}$ & 1.4894 & 12.4530 & 0.9914 & 1.4939 & 12.3520 & 0.9930 \\
7 days & 1.4515 & 12.3970 & 0.9869 & 1.4569 & 12.3230 & 0.9897 \\
15 days & 1.4226 & 12.3060 & 0.9855 & 1.4343 & 12.2370 & 0.9907 \\
30 days & NDA & & & NDA & & \\
\hline
\end{tabular}

ND: Non detectable activity.

Cited on page 7.

E. gallinarum as mutant producing strains. After statistical analysis, the results (Table 14) showed no significant differences between the products in the production of spontaneous mutants for any of the strains tested (Figure 6).

Table 10 Potency of the commercial samples of vancomycin

\begin{tabular}{|c|c|}
\hline Samples & Potency \\
\hline \multicolumn{2}{|l|}{1} \\
\hline 2 & 0.995 \\
\hline 3 & 1.012 \\
\hline 4 & 1.005 \\
\hline 5 & 1.100 \\
\hline 6 & 0.936 \\
\hline 7 & 1.124 \\
\hline 8 & 1.032 \\
\hline \multicolumn{2}{|l|}{9} \\
\hline 10 & 1.064 \\
\hline \multicolumn{2}{|l|}{11} \\
\hline 12 & 1.019 \\
\hline 13 & 1.023 \\
\hline 14 & 1.150 \\
\hline 15 & 1.108 \\
\hline 16 & 0.9859 \\
\hline 17 & 1.107 \\
\hline 18 & 1.047 \\
\hline \multicolumn{2}{|l|}{19} \\
\hline 20 & 0.981 \\
\hline 21 & 1.019 \\
\hline 22 & 1.011 \\
\hline \multicolumn{2}{|l|}{23} \\
\hline 24 & 1.003 \\
\hline 25 & 1.023 \\
\hline 26 & 1.011 \\
\hline 27 & 0.961 \\
\hline \multicolumn{2}{|l|}{28} \\
\hline 29 & 1.062 \\
\hline 30 & \\
\hline
\end{tabular}

Cited on pages 7 and 9.

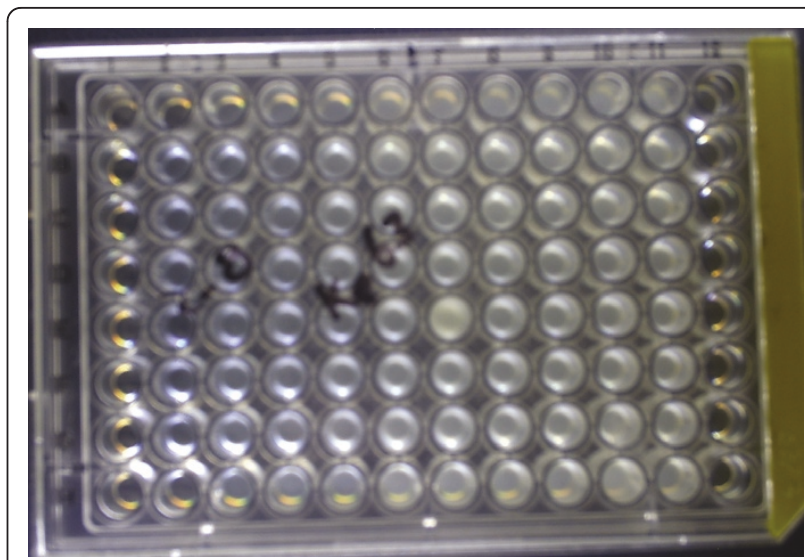

Figure 3 MIC assays of vancomycin products against $K$. pneumoniae 63.

\section{Discussion}

Despite the fact that USP Pharmacopoeia assesses the bioassay conditions for vancomycin evaluation, the bioassay was validated following the suggestions of the

\section{Table 11 Determination of MICs and MBCs for} Vancomycin (USP standard)

\begin{tabular}{ccccccc}
\hline Microorganism & \multicolumn{3}{c}{ MIC $(\boldsymbol{\mu g} / \mathbf{m l})$} & \multicolumn{3}{c}{ MBC $(\boldsymbol{\mu g} / \mathbf{m l})$} \\
\cline { 2 - 7 } & Std & M1 & M2 & Std & M1 & M2 \\
\hline A. baumanii 59 & 62.06 & 62.06 & 62.06 & 124.13 & 124.13 & 124.13 \\
A. baumanii 139 & 124.13 & 124.13 & 124.13 & 248.25 & 248.25 & 248.25 \\
A. baumanii 147 & 993 & 993 & 993 & ND & ND & ND \\
A. baumanii 173 & 62.06 & 62.06 & 62.06 & 124.13 & 124.13 & 124.13 \\
E. faecalis & 1.93 & 1.93 & 1.93 & 3.88 & 3.88 & 3.88 \\
E. faecalis ATCC 29212 & 7.76 & 7.76 & 7.76 & 15.52 & 15.52 & 15.52 \\
E. faecalis 319623 & 62.06 & 62.06 & 62.06 & 124.13 & 124.13 & 124.13 \\
E. gallinarum & ND & ND & ND & 124.13 & 124.13 & 124.13 \\
E. coli 39 & 124.13 & 124.13 & 124.13 & 248.25 & 248.25 & 248.25 \\
E. coli 50 & 124.13 & 124.13 & 124.13 & 248.25 & 248.25 & 248.25 \\
E. coli 69 & 496.50 & 496.50 & 496.50 & 993.00 & 993.00 & 993.00 \\
K. pneumoniae 1 & ND & ND & ND & 496.50 & 496.50 & 496.50 \\
K. pneumoniae 43 & 496.5 & 496.5 & 496.5 & 993.00 & 993.00 & 993.00 \\
K. pneumoniae 63 & 993.00 & 993.00 & 993.00 & ND & ND & ND \\
K. pneumoniae 65 & 993.00 & 993.00 & 993.00 & ND & ND & ND \\
K. pneumoniae 207 & 496.00 & 496.00 & 496.00 & 993.00 & 993.00 & 993.00 \\
Ps. aeruginosa 42 & 1.94 & 1.94 & 1.94 & 3.88 & 3.88 & 3.88 \\
P. aeruginosa 74 & 1.94 & 1.94 & 1.94 & 3.88 & 3.88 & 3.88 \\
Ps. aeruginosa 151 & 993.00 & 993.00 & 993.00 & ND & ND & ND \\
P. aeruginosa 157 & 993.00 & 993.00 & 993.00 & ND & ND & ND \\
Ps. aeruginosa HE1 & 993.00 & 993.00 & 993.00 & ND & ND & ND \\
St. Aureus 287 & 1.94 & 1.94 & 1.94 & 3.88 & 3.88 & 3.88 \\
St. Aureus 291 & 1.94 & 1.94 & 1.94 & 3.88 & 3.88 & 3.88 \\
St. Aureus ATCC 25923 & 1.94 & 1.94 & 1.94 & 3.88 & 3.88 & 3.88 \\
M. morganii HE2 & 496.50 & 496.50 & 496.50 & 993.00 & 993.00 & 993.00 \\
\hline Cited on pages 7 and 9. & & & & & &
\end{tabular}




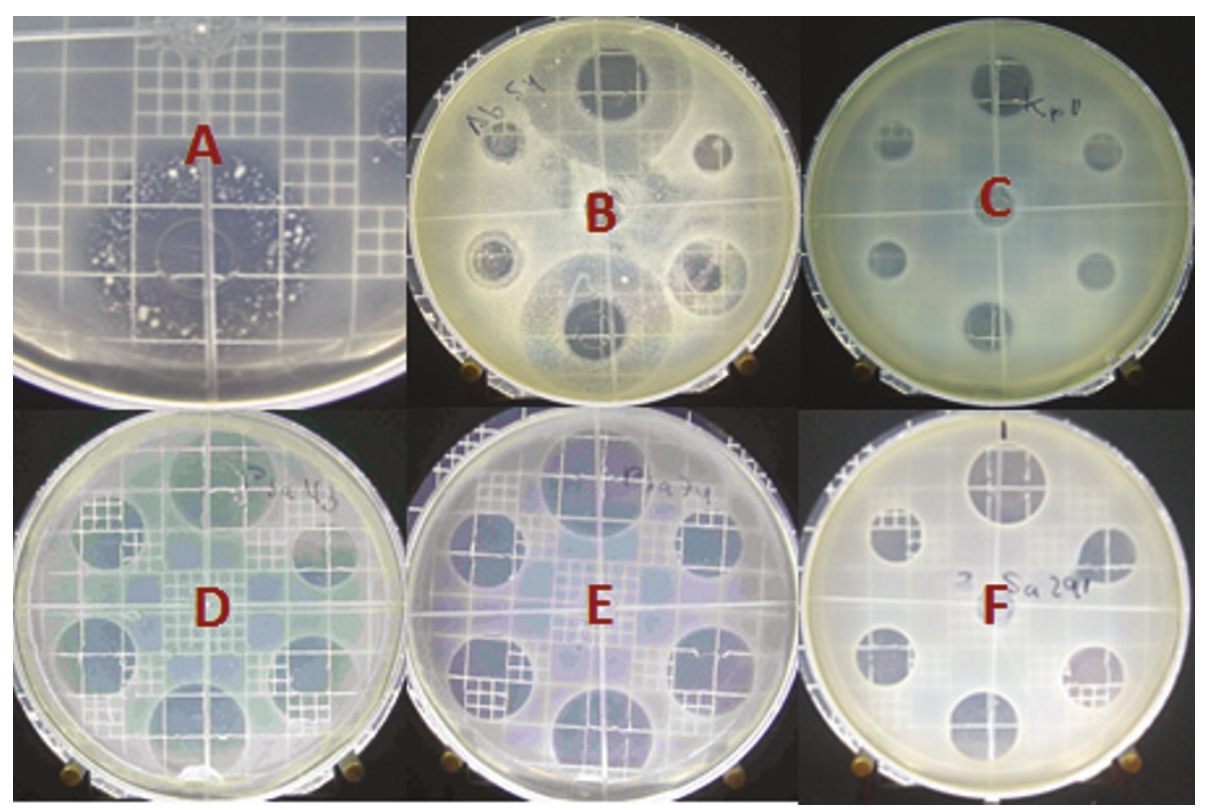

Figure 4 Zones of inhibition produced by Vancomycin against (A) E. gallinarum, (B) A. baumanii 54, (C) K. pneumoniae 1, (D) P. aeruginosa 43, (E) P. aeruginosa 74 and (F) S. aureus 291.

specialized literature [1-3], to assure the certainty of results concerning the sample contents. The experiment to evaluate assay performance showed that it fulfilled the assay requirements (linearity, repeatability, precision). In the assay, the best linearity was shown over the range of $251.25 \mu \mathrm{g} / \mathrm{ml}$ to $7.85 \mu \mathrm{g} / \mathrm{ml}$, i.e., the correlation was the highest $\left(R^{2}=0.9907\right)$. The reproducibility and between-day precision of both assays had coefficients of variation less than $1 \%$, and ANOVA showed no significant differences at any concentration. Antibiotic activity remained stable over the course of the assay at the selected temperature. Finally, the inhibition assay results were due only to the molecules evaluated. In conclusion,

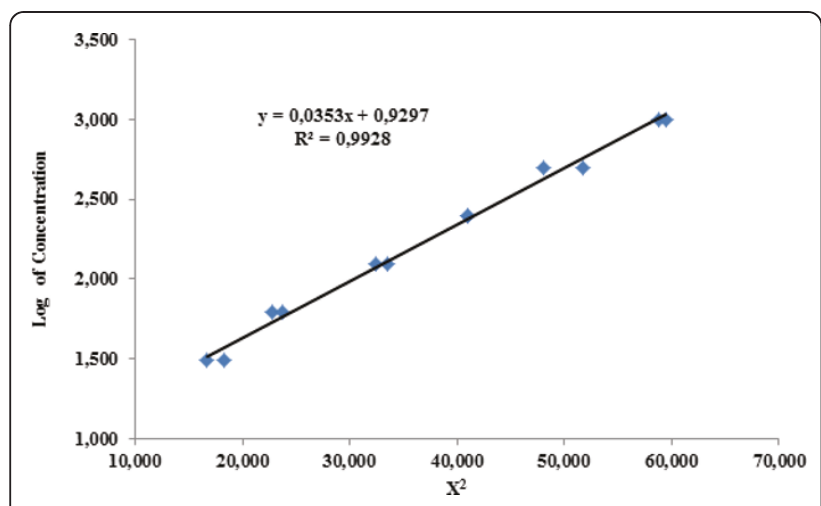

Figure 5 Determination of critical concentration of Vancomycin against $P$. aeruginosa 74 . the assay was exact and accurate with reproducible results.

Our results were generally similar to those of Zuluaga et al. (2009), but with some differences. Zuluaga et al. (2009) proposed a comparison of the performances of all samples by linear correlation against the performance of the original compound to determine pharmaceutical equivalence. This approach is problematic because the commercial products exhibit some differences in their potency. The USP Pharmacopoeia XXVII states “...Contents no less than $90 \%$ and no more than $115 \%$ of Vancomycin, calculated on anhydrous base of the quantity registered of Vancomycin", are acceptable. Therefore, if we use a reference element for which there is uncertainty about its content, a sample could be assessed against different potencies. For example, if the commercial sample has $90 \%$ of the potency of Vancomycin, the potency of the sample under study will be overvalued, but if the reference sample has $115 \%$ of the potency, the sample under study will be undervalued. Finally, we strongly recommend that an antibiotic must be evaluated against an international reference standard by established and validated bioassays using an appropriate test microorganism and conditions. Then, the conclusions about the samples contents will be certain.

Analyses of commercial versions of the antibiotics tested (brand-name and generic products) indicate that all of the samples can be considered pharmaceutical equivalents because they all fulfill the standards of the USP Pharmacopoeia (Table 10). In the study by Zuluaga 
Table 12 Critical concentrations $(\mu \mathrm{g} / \mathrm{ml})$ of different samples of Vancomycin against various microorganisms.

\begin{tabular}{|c|c|c|c|c|c|c|c|c|c|c|}
\hline Sample & E. $f$. & E. f. 29212 & E. f. 319623 & A. b. 59 & E. $g$. & P. a. 43 & P. a. 74 & S. a. 281 & S. a. 291 & S. a. 25923 \\
\hline Standard & 13.251 & 14.098 & 26.733 & 7.712 & 14.725 & 10.932 & 8.586 & 9.951 & 12.473 & 13.108 \\
\hline M2 & 13.332 & 14.173 & 26.826 & 7.735 & 14.850 & 10.988 & 8.646 & 10.044 & 12.558 & 13.164 \\
\hline M3 & 13.050 & 14.170 & 26.505 & 7.759 & 14.993 & 10.977 & 8.745 & 10.032 & 12.764 & 13.410 \\
\hline M4 & 13.166 & 14.041 & 26.630 & 7.670 & 15.076 & 10.870 & 8.635 & 9.991 & 12.682 & 13.202 \\
\hline M5 & 12.961 & 14.566 & 26.160 & 8.305 & 14.798 & 11.716 & 9.474 & 10.941 & 13.753 & 14.662 \\
\hline M6 & 14.495 & 13.338 & 28.017 & 7.355 & 13.974 & 10.308 & 8.016 & 9.280 & 11.725 & 12.324 \\
\hline M7 & 12.523 & 14.237 & 26.540 & 7.856 & 16.029 & 12.348 & 9.666 & 11.143 & 14.076 & 14.729 \\
\hline M8 & 13.441 & 13.627 & 27.530 & 8.053 & 15.008 & 11.248 & 8.903 & 10.138 & 13.220 & 13.440 \\
\hline M13 & 13.052 & 14.193 & 26.574 & 8.003 & 14.955 & 11.146 & 8.908 & 10.306 & 12.713 & 13.489 \\
\hline M14 & 13.792 & 15.904 & 28.612 & 8.481 & 15.291 & 12.621 & 9.897 & 11.480 & 14.454 & 15.286 \\
\hline M15 & 13.791 & 15.673 & 27.431 & 8.190 & 15.700 & 11.969 & 9.500 & 11.015 & 13.820 & 14.539 \\
\hline M16 & 13.483 & 14.326 & 26.535 & 7.698 & 14.991 & 10.743 & 8.458 & 9.795 & 12.363 & 12.986 \\
\hline M17 & 13.720 & 15.128 & 27.261 & 8.068 & 15.794 & 12.163 & 9.519 & 11.006 & 13.786 & 14.510 \\
\hline M18 & 13.697 & 14.790 & 26.915 & 7.720 & 15.196 & 11.671 & 8.965 & 10.384 & 13.427 & 13.807 \\
\hline M20 & 13.568 & 14.405 & 27.117 & 7.660 & 14.535 & 10.760 & 8.506 & 9.835 & 12.249 & 12.886 \\
\hline M21 & 13.192 & 14.632 & 26.985 & 7.857 & 16.048 & 11.178 & 8.759 & 10.091 & 12.625 & 13.413 \\
\hline M22 & 14.067 & 13.946 & 26.536 & 7.774 & 15.571 & 11.309 & 8.741 & 10.057 & 12.769 & 13.437 \\
\hline M24 & 13.334 & 14.046 & 26.701 & 7.856 & 14.655 & 10.895 & 8.639 & 10.016 & 12.418 & 13.125 \\
\hline M26 & 13.882 & 14.592 & 26.519 & 7.638 & 15.409 & 11.116 & 8.739 & 10.038 & 12.671 & 13.299 \\
\hline M27 & 12.741 & 13.544 & 25.775 & 7.474 & 14.126 & 10.499 & 8.326 & 9.612 & 12.200 & 12.595 \\
\hline M29 & 13.571 & 14.008 & 26.770 & 8.274 & 15.281 & 11.105 & 9.143 & 10.404 & 12.998 & 13.887 \\
\hline
\end{tabular}

Cited on pages 8 and 10

Table 13 Ratios of sample CC/standard CC for Vancomycin

\begin{tabular}{|c|c|c|c|c|c|c|c|c|c|c|c|c|}
\hline \multirow[t]{2}{*}{ SAMPLE } & \multicolumn{10}{|c|}{ MICROORGANISMS } & \multirow[t]{2}{*}{ Ratio Median } & \multirow[t]{2}{*}{ Potency } \\
\hline & E. $f$. & E.f. 29212 & E. f. 319623 & A. b. 59 & E. $g$. & P. a. 43 & P. a. 74 & S. a. 281 & S. a. 291 & S. a. 25923 & & \\
\hline \multicolumn{13}{|l|}{ Standard } \\
\hline M2 & 1.006 & 1.005 & 1.003 & 1.003 & 1.008 & 1.005 & 1.007 & 1.009 & 1.007 & 1.004 & 1.006 & 0.995 \\
\hline M3 & 0.985 & 1.005 & 0.991 & 1.006 & 1.018 & 1.004 & 1.018 & 1.008 & 1.023 & 1.023 & 1.008 & 1.012 \\
\hline M4 & 0.994 & 0.996 & 0.996 & 0.995 & 1.024 & 0.994 & 1.006 & 1.004 & 1.017 & 1.007 & 1.003 & 1.005 \\
\hline M5 & 0.978 & 1.033 & 0.979 & 1.077 & 1.005 & 1.072 & 1.103 & 1.100 & 1.103 & 1.119 & 1.057 & 1.100 \\
\hline M6 & 1.094 & 0.946 & 1.048 & 0.954 & 0.949 & 0.943 & 0.934 & 0.933 & 0.940 & 0.940 & 0.968 & 0.936 \\
\hline M7 & 0.945 & 1.010 & 0.993 & 1.019 & 1.089 & 1.130 & 1.126 & 1.120 & 1.128 & 1.124 & 1.068 & 1.124 \\
\hline M8 & 1.014 & 0.967 & 1.030 & 1.044 & 1.019 & 1.029 & 1.037 & 1.019 & 1.060 & 1.025 & 1.024 & 1.032 \\
\hline M13 & 0.985 & 1.007 & 0.994 & 1.038 & 1.016 & 1.020 & 1.038 & 1.036 & 1.019 & 1.029 & 1.018 & 1.023 \\
\hline M14 & 1.041 & 1.128 & 1.070 & 1.100 & 1.038 & 1.155 & 1.153 & 1.154 & 1.159 & 1.166 & 1.116 & 1.150 \\
\hline M15 & 1.041 & 1.112 & 1.026 & 1.062 & 1.066 & 1.095 & 1.106 & 1.107 & 1.108 & 1.109 & 1.083 & 1.108 \\
\hline M16 & 1.018 & 1.016 & 0.993 & 0.998 & 1.018 & 0.983 & 0.985 & 0.984 & 0.991 & 0.991 & 0.998 & 0.986 \\
\hline M17 & 1.035 & 1.073 & 1.020 & 1.046 & 1.073 & 1.113 & 1.109 & 1.106 & 1.105 & 1.107 & 1.079 & 1.107 \\
\hline M18 & 1.034 & 1.049 & 1.007 & 1.001 & 1.032 & 1.068 & 1.044 & 1.044 & 1.076 & 1.053 & 1.041 & 1.047 \\
\hline M20 & 1.024 & 1.022 & 1.014 & 0.993 & 0.987 & 0.984 & 0.991 & 0.988 & 0.982 & 0.983 & 0.997 & 0.981 \\
\hline M21 & 0.996 & 1.038 & 1.009 & 1.019 & 1.090 & 1.023 & 1.020 & 1.014 & 1.012 & 1.023 & 1.024 & 1.019 \\
\hline M22 & 1.062 & 0.989 & 0.993 & 1.008 & 1.057 & 1.035 & 1.018 & 1.011 & 1.024 & 1.025 & 1.022 & 1.011 \\
\hline M24 & 1.006 & 0.996 & 0.999 & 1.019 & 0.995 & 0.997 & 1.006 & 1.006 & 0.996 & 1.001 & 1.002 & 1.003 \\
\hline M26 & 1.048 & 1.035 & 0.992 & 0.990 & 1.046 & 1.017 & 1.018 & 1.009 & 1.016 & 1.015 & 1.019 & 1.011 \\
\hline M27 & 0.962 & 0.961 & 0.964 & 0.969 & 0.959 & 0.960 & 0.970 & 0.966 & 0.978 & 0.961 & 0.965 & 0.961 \\
\hline M29 & 1.024 & 0.994 & 1.001 & 1.073 & 1.038 & 1.016 & 1.065 & 1.046 & 1.042 & 1.059 & 1.036 & 1.062 \\
\hline
\end{tabular}


Table 14 Spontaneous mutant production in the diffusion gel assay for vancomycin products

\begin{tabular}{|c|c|c|c|c|}
\hline \multirow[t]{2}{*}{ Sample } & \multicolumn{2}{|c|}{ Mutants of $A$. baumanii 54} & \multicolumn{2}{|c|}{ Mutants of $E$. gallinarum } \\
\hline & Median & $\sigma$ & Median & $\sigma$ \\
\hline Standard & 106.17 & 1.47 & 96.500 & 5.089 \\
\hline M2 & 111.00 & 1.00 & 100.667 & 2.082 \\
\hline M3 & 104.33 & 1.53 & 98.333 & 1.528 \\
\hline M4 & 106.67 & 2.08 & 104.667 & 5.686 \\
\hline M5 & 103.67 & 0.58 & 99.000 & 2.000 \\
\hline M6 & 109.00 & 1.00 & 96.000 & 2.000 \\
\hline M7 & 110.67 & 1.53 & 100.667 & 1.155 \\
\hline M8 & 108.67 & 1.53 & 98.667 & 1.155 \\
\hline M10 & 104.00 & 1.73 & 95.667 & 1.528 \\
\hline M12 & 110.67 & 1.53 & 93.333 & 2.517 \\
\hline M13 & 106.33 & 1.53 & 94.000 & 3.000 \\
\hline M14 & 106.67 & 2.52 & 101.000 & 1.000 \\
\hline M15 & 110.67 & 1.15 & 99.333 & 1.155 \\
\hline M17 & 105.33 & 1.15 & 93.667 & 3.786 \\
\hline M18 & 104.33 & 2.08 & 96.000 & 1.000 \\
\hline M20 & 109.33 & 1.53 & 100.667 & 0.577 \\
\hline M22 & 112.00 & 1.00 & 103.000 & 3.000 \\
\hline M24 & 105.33 & 1.53 & 96.000 & 1.000 \\
\hline M26 & 109.33 & 1.53 & 100.667 & 0.577 \\
\hline M27 & 112.00 & 1.00 & 103.000 & 3.000 \\
\hline M29 & 105.33 & 1.53 & 96.000 & 1.000 \\
\hline$F$ & \multicolumn{2}{|c|}{10.026} & \multicolumn{2}{|c|}{4.424} \\
\hline Prob. & \multicolumn{2}{|c|}{0.001} & \multicolumn{2}{|c|}{0.005} \\
\hline VCF & \multicolumn{2}{|c|}{1.706} & \multicolumn{2}{|c|}{1.706} \\
\hline
\end{tabular}

Cited on page 9

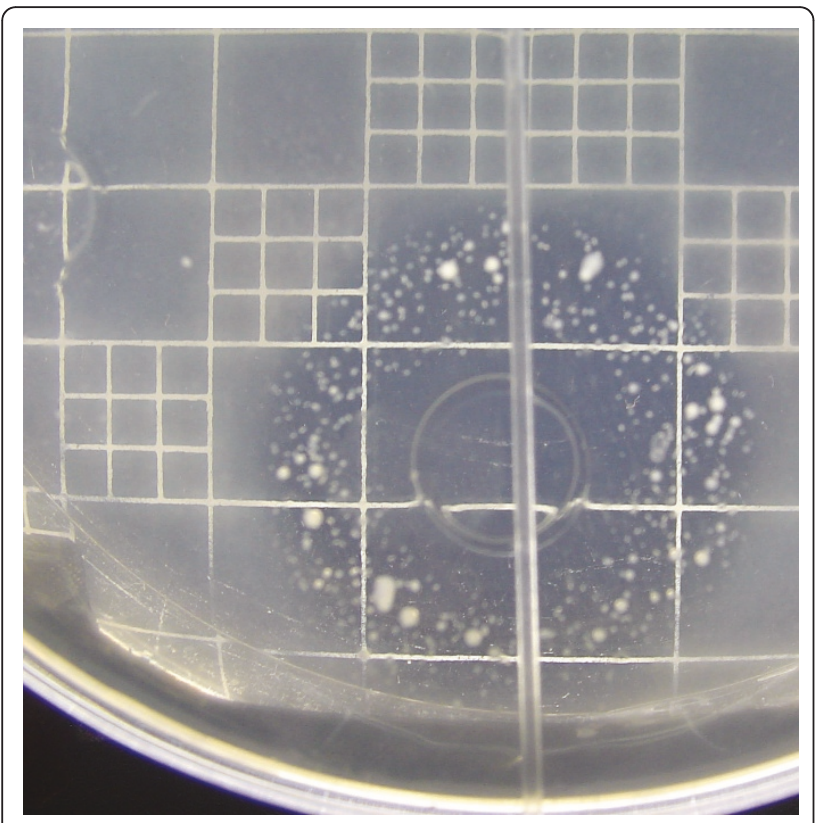

Figure 6 Production of spontaneous vancomycin-resistant mutants of $E$. gallinarum. et al. (2009), the performance of all samples was similar to the innovator, and the results were accurate and reproducible, which means that all of the producers of this antibiotic are using similar parameters to manufacture their products.

The MIC and MBC results obtained with different pathogenic strains showed no differences between samples (Tables10 and 11), which is probably because the samples were pharmaceutical equivalents. We conclude that generic and novel products perform equally well. In other words, the generic products evaluated in this study fulfill the requirements to be considered for use in antimicrobial therapy.

We also designed an assay to determine critical concentrations using a few selected strains to confirm that all of the generic products evaluated were effective in antimicrobial therapy. The results showed no significant differences among samples (Table 12). Moreover, the ratios between the $\mathrm{CC}$ of the standard and those of the different samples were similar to their potency levels (Tables 13).

Along the same lines, an assay was designed to determine the production of spontaneous mutants in diffusion gel assays. The results again showed that all the samples behaved similarly, leading us to conclude that none of the samples studied markedly differ in their antimicrobial activities. That is, generic and brand name products that comply with the international specifications for manufacturing pharmaceutical products behave similarly to novel products.

Our results are different from those of other studies $[5,6]$. Those studies were conducted using the newest product as a "standard of comparison," but the researchers did not take into account that a commercial product may have a range of content between $90 \%$ and $120 \%$. Consequently, there would be great variability in the results with respect to the performance of the antibiotic. For instance, if the novel drug product has a hypothetical content of $120 \%$ relative to the declared content on the label, and the generic product has a hypothetical content of $90 \%$, then the effective content of the generic product would be $75 \%(90 / 120)$ of the novel drug. This scenario could produce misleading results because although both products fulfill the content requirements, the first is at the upper limit and the second at the lower limit.

It has been proposed that generic antibiotics behave differently from innovator products against pathogenic microorganisms $[5,6]$. This is possible if the generic antibiotic does not fulfill the quality standards for that pharmaceutical product (e.g., purity or content). For instance, contaminants in generic drugs could interfere with their antibiotic activities.

Vesga et al (2009) reported that none of the vancomycin products have differences in in vitro assays; they had 
no differences in potency, MIC or MBC. Also, in time-kill curves and single-dose serum Pharmacokinetics (PK) in infected mouse there were no differences. However, the pharmacodynamic study had very odd results; the products tested did not behave like the innovator in vitro. We think that these results should be reanalyzed or retested because at the lower concentration, the generics have a better antimicrobial activity than the innovator, but in the higher concentrations, these behaviors change. The free antibiotic in the serum is the only chemical responsible for the antimicrobial activity and they showed in the PK model that all of the antibiotics diffuse into the blood in an equivalent way; so, they should behave against the same microorganism in an equivalent way.

\section{Conclusions}

All of the samples analyzed by standardized, microbiological methods fulfill the requirements for content according to USP XXVII. They all show the same antimicrobial behavior because they have similar MIC, MBC and $C C$ values and produce similar numbers of mutants.

\section{Abbreviations}

MIC: Minimal Inhibitory Concentration; MBC: Minimal Bactericidal Concentration; CC: Critical Concentration; C1: Concentration 1; C2: Concentration 2; C10: Concentration 10; A. b.: Acinetobacter baumanii; S. f.: Streptococcus faecalis; E. g.: Enterococcus gallinarum; E. c.: Escherichia coli; K. p.: Klebsiella pneumonia; P. a.: Pseudomonas aeruginosa; S. a.: Staphylococcus aureus; M1: Sample 1; M2: Sample 2, ...
}

\section{Acknowledgements}

The authors wish to express their gratitude to VITALIS PHARMACEUTICAL, for its support of this collaborative research, a joint venture between Vitalis S.A. and the National University of Colombia.

\section{Author details}

'Universidad Nacional de Colombia, Facultad de Ciencias, Departamento de Farmacia, Laboratorio de Asesorías e Investigaciones en Microbiología, 472. Ciudad Universitaria. Carrera 30 Calle 45. A.A.14490. Bogotá D. C. Colombia.

${ }^{2}$ Vitalis Pharmaceutical, Proyectos Especiales, Carrera 7 No 156-80. Oficina No 1104. Bogotá D. C. Colombia.

\section{Authors' contributions}

MG, a student at the National University of Colombia, jointly developed a process to validate the quantitative assay for vancomycin for their theses in Pharmaceutical Chemistry. MJA was the project administrator and contributed to article redaction. JAD and ES conceived the study, obtained necessary funding, designed and directed the execution and analysis of data, edited the manuscript and approved it for publication.

All the authors read and are in agreement with the whole all of article text.

\section{Competing interests}

Diaz and Silva received financial support for lectures from Vitalis S. A. to participate in national scientific meetings in Colombia. The present study was a joint venture between the Science Faculty of National University of Colombia and Vitalis Pharmaceutical. And was also financed by Vitalis Pharmaceutical.

Received: 13 December 2010 Accepted: 21 July 2011

Published: 21 July 2011

\section{References}

1. CENTERS FOR DISEASE CONTROL AND PREVENTION, FOOD AND DRUG ADMINISTRATION, NATIONAL INSTITUTES OF HEALTH. A Public Health Action Plan to Combat Antimicrobial Resistance;[http://www.cdc.gov/ drugresistance/pdf/2010/Interagency-Action-Plan-PreClearance-03-2011.pdf].

2. THE UNITED STATES PHARMACOPOEIA. XXVII. Biological test and assays Pharmacopoeia Convention Inc Bronx New York USA; 1883, 358.

3. INTERNATIONAL CONFERENCE ON HARMONISATION OF TECHNICAL REQUIREMENTS FOR REGISTRATION OF PHARMACEUTICALS FOR HUMAN USE. Validation of Analytical Procedures: Text and Methodology. Q2 (R1). Current Step 4 version. Parent Guideline dated 27 October 1994 (Complementary Guideline on Methodology dated 6 November 1996 incorporated in November 2005).

4. Jones RN, Fritsche TR, Moet GJ: In vitro potency evaluations of various piperacillin/tazobactam generic products compared with the contemporary branded (Zosyn ${ }^{\oplus}$, Wyeth) formulation. Diagnostic Microbiology and Infectious Disease 2008, 61:76-79.

5. Moeta JGary, Wattersa AAmy, Sadera SHelio, Jonesx NRonald: Expanded studies of piperacillin/Tazobactam formulations: variations among branded product lots and assessment of 46 generics lots. Diagnostic Microbiology and Infectious Disease 2009, 65:319-322.

6. Zuluaga AF, Agudelo M, Rodriguez CA, Vesga O: Application of microbiological assay to determine pharmaceutical equivalence of generic intravenous antibiotics. BMC Clinical Pharmacology 2009, 9:1.

7. Vesga O, Agudelo M, Salazar BE, Rodriguez CA, Zuluaga F: Generic products of vancomycin fail in vivo despite being pharmaceutical equivalents of the innovator. Antimicrob Agents Chemother 2010, 54:3271-3279.

8. Melendez P, Diaz J, Silva E, Gonzales P, Gonzalez P, Moreno E, Amaya P, Serrato N, Saenz E: Estudio comparativo de la actividad antimicrobiana de diferentes presentaciones comerciales de antibióticos de administración intravenosa a través de métodos in vitro. Revista Colombiana de Ciencias Químico-Farmacéuticas 2005, 34.

9. Silva E, Diaz JA, Arias MJ, Hernadez AP, De La Torre A: Comparative in vitro study of the antimicrobial activities of different commercial antibiotic products for intravenous administration. BMC Clinical Pharmacology 2010, 10:3.

10. Lorian $V$, (Ed.): Antibiotics in Laboratory Medicine. Williams \& Wilkins. Baltimore; 1980, 95-98.

\section{Pre-publication history}

The pre-publication history for this paper can be accessed here: http://www.biomedcentral.com/1472-6904/11/9/prepub

doi:10.1186/1472-6904-11-9

Cite this article as: Diaz et al:: Comparative in vitro study of the antimicrobial activities of different commercial antibiotic products of vancomycin. BMC Clinical Pharmacology 2011 11:9.

\section{Submit your next manuscript to BioMed Central and take full advantage of:}

- Convenient online submission

- Thorough peer review

- No space constraints or color figure charges

- Immediate publication on acceptance

- Inclusion in PubMed, CAS, Scopus and Google Scholar

- Research which is freely available for redistribution 